\title{
UPRAVLJANJE ORGANIZACIONO
} KOMERCIJALNIM RIZICIMA U ZDRAVSTVENOM TURIZMU SRBIJE KROZ MARKETING MENADŽMENT KONCEPT

\section{MANAGEMENT OF SERBIAN HEALTH TOURISM ORGANIZATIONAL AND COMMERCIAL RISKS THROUGH MARKETING MANAGEMENT CONCEPT}

\section{Jovanka Popović}

Visoka škola za poslovnu ekonomiju i preduzetništvo, Beograd, Srbija

\section{Vlado Radić}

Visoka škola za poslovnu ekonomiju i preduzetništvo, Beograd, Srbija

\section{Rade Stanković}

Visoka škola za poslovnu ekonomiju i preduzetništvo, Beograd, Srbija

\section{() MESTE NGO}

JEL category: H12, I11, L83, M3

\begin{abstract}
Apstrakt
Upravljanje organizacionim i komercijalnim rizicima u zdravstvenom turizmu kroz koncept marketing menadžmenta, doprinosi održivom uspehu zdravstvenog turizma, što podrazumeva poslovni uspeh u kontinuitetu, održivi razvoj, socijalnu odgovornost i poslovnu etiku, jer nema razvoja i progresa ako se isti ne shvate kao prioritet od opšteg značaja za sam razvoj.

Marketing menadžment u zdravstvenom turizmu treba shvatiti kao modernu orijentaciju, koja prerasta okvire klasičnih organizacionih struktura i vodi mnogo kompleksnijem načinu mišljenja, otvarajući horizonte na kojima konzervativno vođenje turističkih organizacija ne vidi svoje šanse.

Rad ima za cilj da oceni stanje zdravstvenog turizma u Republici Srbiji i sagleda realne opasnosti u okviru ukupne turističke ponude, sa zadatkom koji se zasniva na ulozi marketing menadžmenta kroz orijentaciju na upravljanje organizacionim i komercijalnim rizicima, i mogućnostima unapređenja dostignutog stepena razvoja zdravstvenog turističkog proizvoda, sledeći trendove razvoja ka ciljnom tržitšu relevantnih informacija, neophodnih za donošenje strateških poslovnih odluka, kroz date savete za sproveđenje istih.
\end{abstract}

Ključne reči: marketing menadžment, zdravstveni turizam, organizacini rizici, komercijalni rizici

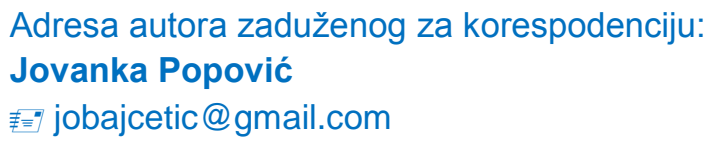

\section{Abstract}

Management of the organizational and commercial risks in health tourism through the concept of 
marketing management, contributes to a sustainable success of health tourism, including continuous business success, sustainable development, social responsibility and business ethics, because there can be neither development nor progress, if they are not perceived as a priority for the overall progress. Marketing management in health tourism should be perceived as a modern orientation, which outgrows the framework of the classic organizational structure and leads to much more complex mindset, opening horizons where conservative management of tourism organizations does not see its chance.

The paper aims to assess the state of health tourism in the Republic of Serbia and identify the real threats within the overall tourism offer, with the task based on the role of marketing management through the orientation on organizational management and commercial risks and opportunities for the improvement of the achieved development level of health tourism product, following development trends towards the target market of relevant information necessary to make strategic business decisions, with consistent advice for their implementation.

Keywords: marketing management, health tourism, organizational risks, commercial risks

\section{UVOD}

Činjenica je da se vrednosti zdravstvenoturističkih destinacija koje predstavljaju velike potencijale i prirodne resurse od nacionalnog značaja, mogu očuvati samo aktivnom i kontinuiranom zaštitom, koja predstavlja jedan od prioriteta u samom razvoju (Jovcic, 2008, p. 4).

Svesni smo toga da se svet sve više okreće zdravom životu i provođenju odmora u čistim, nezagađenim sredinama, sa zdravom hranom i svežim vazduhom. Mnoga područja u Srbiji su već stekla zavidnu reputaciju zdravstveno-turističkih destinacija. Svakako, usvajanjemkoncepta održivog razvoja i upravljanja zdravstvenim turizmom, uz korišćenje iskustava drugih zemalja, može se doprineti odgovarajućem pozicioniranju Srbije kao zavidne turističke destinacije na međunarodnom turističkom tržištu, što treba da doprinese razvoju turizma $i$ istovremeno obezbedi veći priliv stranih turista i stranog novca.

Dok se u svetu beleži porast od 15 do 20 odsto godišnje, Srbija pati od nedostatka sadržaja i organizovane ponude zdravstvenog turizma, čak i $\mathrm{u}$ onim turističkim destinacijama koje $\mathrm{u}$ tom segmentu imaju tradiciju, izvrsne prirodne, kadrovske i društvene resurse.

Zbog velikog broja atraktivnih prirodnih i antropogenih turističkih resursa, Republika Srbija ima dobru osnovu za brži zdravstveno-turistički razvoj, a time i svestraniji privredni razvoj u celini, imajući u vidu to, da je turizam komplementarna delatnost sa mnogim drugim privrednim granama (poljoprivreda, trgovina, saobraćaj i dr.) (Popovic\& al., 2013).

Naime, zdravstveni turizam predstavlja vrstu turističkih aktivnosti u kojoj bitno mesto zauzima stručno i kontrolisano korišćenje prirodnih lekovitih elemenata, postupaka fizikalne medicine i programiranih fizičkih aktivnosti u svrhu održanja i unapređenja fizičkog, psihičkog i/ili duhovnog zdravlja turista, a u cilju poboljšanja kvaliteta njihovog života (Kunst \& Tomljenovic, 2011, p. 57).

Dobro očuvana priroda predstavlja jednu od fundamentalnih i konkurentskih prednosti razvoja turizma Srbije, dok raznovrsnost prirodnih i zdravstveno-turističkih resursa postaje dodatni razlog da se razvoj turizma smatra važnim sredstvom održivog razvoja kroz konzistentni i dugoročni pristup (Popovic, 2012).

Sa aspekta zdravstvenog turizma posebno su interesantni resursi biosfere (voda, vazduh, flora, fauna i sl.), zatim sunčeva svetlost i toplota (Rikalovic, 1999, p. 31-32).

Upravo iz navedenih razloga neophodnih za razvoj zdravstvenog turizma, posebnu pažnju treba posvetiti ulozi marketing menadžmenta, koji zahteva određenu regulaciju, gde bi outputi bili tržišno, poslovno i društveno prihvaćeni. Zato je zdravstvenom turizmu, kroz marketing menadžment, potrebno pristupiti kao procesu koji se sastoji iz planiranja, kontrole i organizovanja, kako bi se smanjila neizvesnost $u$ pogledu očekivanog ishoda. Suština te neizvesnosti proizlazi iz nedovoljnosti i nepouzdanosti informacija, na osnovu kojih se donose neophodne odluke za ostvarenje cilja. Mnoštvo tih odluka sračunato je na ostvarenje budućih rezultata privređivanja, odnosno poslovnog dobitka, gde je „cilj da se otklone slabosti i poveća stepen satisfakcije kroz ispunjenje i eventualno prevazilaženje očekivanja" turista (Sekulovic, 2009). 
2 ULOGA MENADŽMENTA U RAZVOJU ZDRAVSTVENOG TURIZMA U SRBIJI

Poznato je da zdravstveni turizam predstavlja najstariji specifični oblik turizma u okviru kojeg se stručno i kontrolisano koriste prirodni i lekoviti faktori, kao i postupci fizikalne terapije u cilju očuvanja i unapređenja zdravlja (Lazovic, 2011). Osnovu razvoja zdravstvenog turizma čini upotreba prirodnih i lekovitih faktora koji u Srbiji mogu biti banjski i klimatski. U banjama se nudi uravnotežena ishrana, isključenost od buke i zagađenja vazduha, fizička aktivnost, društveni i duhovni programi, a činjenica da u Srbiji ima preko 50 zdravstveno-lečilišnih destinacija, kao i da je nesumnjiv kvalitet termalnih voda na kojima je bazirana njihova ponuda, predstavlja veliki razvojni potencijal Srbije za budućnost.

Neuvažavanje koncepta održivog razvoja u zdravstveno-turističkoj oblasti, dovelo je u proteklom periodu do niza negativnih efekata, čime su ugroženi prirodni i lekoviti faktori i celokupan ambijent zdravstveno-turističkih mesta. Zato, zdravstveni turizam zaslužuje ne samo posebne mere zaštite uz adekvatnu odgovornost javnog i privatnog sektora, nego i adekvatno upravljanje i organizovanje. Da bi se otklonile moguće posledice i obezbedila prevencija negativnih efekata $u$ zdravstvenom turizmu, pažnja se mora posvetiti ne samo zakonskim i prostorno-planskim aktivnostima, nego i organizacionim, informacionim, upravljačkim i edukativnim merama.

Svim navedenim merama može se pristupiti kroz modernu orijentaciju, koja prerasta okvire klasičnih organizacionih struktura i vodi mnogo kompleksnijem načinu mišljenja, otvarajući horizonte na kojima zdravstveno-turističke organizacije vide svoje šanse, gde je prvenstveni cilj tržišno pozicioniranje, prepoznatljivost i, naravno, profit. Pomenuta moderna orijentacija govori o koncepciji marketing menadžmenta, u kojoj kupac (potrošač) igra glavnu ulogu, proizvod sporednu, gde se konkurencija guši, a lojalnost obezbeđuje savršenom ponudom kroz etičke vrednosti. Druga strana koncepta orijentisana je ka očuvanju i zaštiti potencijalnih resursa, ređe usluzi, pa tek onda profitu i samoodrživosti. Po ovom konceptu konkurencija se prihvata, nekada čak i podržava ustupanjem ljudskih i tehničkih resursa.

Marketing menažment predstavlja stub na kome centralno mesto imaju kreatori zdravstvenoturističkog proizvoda, lokalna zajednica i turistička organizacija, koji kroz saradnju i partnerstvo ostvaruju zajednički interes. To zahteva prilagođavanje zbog stalnih promena, ubrzane globalizacije, rastuće konkurencije, novih tehnologija, imperativa kvaliteta, inovacija itd. (Krasojevic, 2011, p. 297)

Savremena marketing menadžment orijentacija zahteva da se poslovne odluke donose na bazi ekonomskih zakonitosti ponude i tražnje, uz proaktivno i podsticajno izazivanje tražnje. S obzirom da zdravstveni turizam ima dosta specifičnosti, neophodno je odstupiti od uobičajenih pravila funkcionisanja i pristupiti kroz koncepciju marketing menadžmenta.

Primena marketing menadžmenta $u$ zdravstvenom turizmu je specifična, pre svega zbog razlike u upravljanju materijalizovanim proizvodima u odnosu na upravljanje uslugama, kao i zbog heterogenosti turističkog tržišta. Marketing menadžment u zdravstvenom turizmu predstavlja fokus na veći broj faktora, određenu sistematičnost u redosledu poteza, a sve sa ciljem utvrđivanja odgovarajuće strategije i politike razvoja, koja će doprineti ostvarenju postojećih ciljeva svake konkretne zdravstveno-turističke ponude (Zupanovic, 2011).

Marketing menadžment u zdravstvenom turizmu treba da bude koncipiran tako da smanji, a po mogućnosti potpuno eliminiše rizike, jer predstavlja pokretačku snagu za koncipiranje strategijskog razvoja zdravstvenog turizma.

\section{UPRAVLJANJE RIZICIMA KROZ MARKETING MENADŽMENT U ZDRAVSTVENOM TURIZMU SRBIJE}

Životna sredina u kojoj se poslovni dogovori odnose na subjekte turisitčke privrede stalno se menja. Većina problema sa kojima se marketing menadžment suočava, isključivo se baziraju na:

- nedostatku informacija,

- čestom redefinisanju problema, 
- nepostojanju programa za njihovo rešavanje,

- uticaju više od jedne osobe, kao i

- dugoročnom karakteru problema.

Karakteristike loše stukturiranih problema odnose se na (Bass, 1983, p.13):

1. nemogućnost adekvatne saglasnosti kod rešavanja mogućih problema,

2. nepostojanje odgovora 0 primeni metodologije za postizanje ciljeva,

3. nemogućnost jasno definisanog programa iz kontrolisanih, nekontrolisanih $\mathrm{i}$ promenljivih ciljeva,

4. probleme koji se sastoje od velikog broja međusobno zavisnih problema.

U turizmu, samim tim i zdravstvenom turizmu, postoje brojna ograničenja koja, pod pretpostavkom nepromenjene životne sredine, otežavaju sprovođenje racionalnog modela donošenja upravljačkih odluka. To je osnovni razlog zašto je u praksu neophodno uvesti marketing menadžment koncipiran da smanji, po mogućnosti potpuno eliminiše rizike, jer isti predstavljaju pokretačku snagu za koncipiranje strategijskog razvoja zdravstvenog turizma.

Da bi se rizici adekvatno kontrolisali pri razvoju zdravstvenog turizma u Republici Srbiji, turističke organizacije koje su prihvatile koncepciju marketing menadžmenta kao poslovnu filozofiju, trebaju istu shvatiti kao polaznu i glavnu orijentacionu tačku ukupnog sistema planiranja, kontrole i organizovanja.

Kako bi se postigla efikasnost i konzistentnost $u$ upravljanju rizicima kroz koncepciju marketing menadžmenta, najvažnije je pravilno delegirati odgovornosti i ovlašćenja za realizovanje plana, tj. stvoriti takvu organizacionu konfiguraciju marketing menadžmenta, koja treba da garantuje kretanje zdravstvenog turizma željenom putanjom ka definisanim ciljevima.

Ciljevi marketing menadžmenta trebaju biti usklađeni $\mathrm{s}$ ciljevima rada i poslovanja zdravstveno-turističkih centara, jer zdravstveni turizam predstavlja jedan od najjačih trendova putovanja u poslednje vreme. Tome je, naravno, doprinela svest ljudi koji brinu za sopstveno zdravlje, ali i promene u načinu rada i života savremenog društva (Cavlek \& al., 2011, p. 355359).

U zdravstvenom turizmu se "zahteva veći stepen fleksibilnosti i adaptibilnosti u odnosu na promenljive uslove u okruženju, gde postoji visok stepen neizvesnosti, gde se menjaju ekonomski uslovi poslovanja i struktura tržišta" (Cerovic, 2003). Tako da uloga marketing menadžmenta mora imati značajnu mesto pri samom razvoju, s obzirom da se u kontinuitetu pojavljuju nove forme i oblici rizika. Stav prema riziku utiče na izbor strategije (Cerovic, 2002) marketing menadžmenta, što može da varira od lakog (ili jednostavnog) prihvatanja, do izbegavanja rizika. $U$ privrednim granama kao što je turizam, (posebno kada se govori o specifičnom zdravstvenom turizmu), rizik teško može da se izbegne (Pearce \& al., 1988, p. 307).

Kroz okvirna načela upravljanja rizicima shvata se (Hornung \& al., 1999, p. 317-325):

- da su rizici nužno povezani s postizanjem uspeha,

- da nijedna aktivnost ili odluka ne sme povlačiti rizik opstanka organizacije,

- da rizici prihoda moraju biti primereno nagrađeni ostvarenim profitom,

- da rizike treba usmeriti instrumenatima upravljanja rizicima u zdravstvenom turizmu.

Kako bi se smanjio rizik, a imajući u vidu tradicionalni pristup zdravstvenom turizmu, neophodno je da se upravljanje istim posmatra kao deo koncepta marketing menadžmenta. Iz ovih razloga marketing menadžment treba da bude poslovna koncepcija, koja pored planiranja, kontrole i organizovanja, obuhvata i upravljanje organizacionim i komercijalnim rizicima. U ovakvoj koncepciji, osnovno kohezivno polje usmereno je na oblast ciljeva, tj. na uticaj pojedinih funkcija za razvoj zdravstvenog tuizma u Republici Srbiji.

\subsection{Organizacioni rizici}

Odluke u organizacionoj strukturi treba da se donose $u$ okviru koncepcije marketing menadžmenta, jer efikasna primena nije takva da odgovora šansama i ograničenjima zdravstvenog turizma. Razvoj marketing menadžment koncepcije ne prevazilazi zahteve trenutne strategije razvoja zdravstvenog turizma, tako da se mora usmeriti na organizacioni sistem koji obezbeđuje rezervni potencijal u uslovima brzih promena u okruženju.

U procesu upravljanja organizacionim rizicima kroz koncepciju marketing menadžmenta, posebna pažnja usmerava se na okvir i 
determinante organizovanja strateškog plana razvoja zdravstvenog turizma, jer se organizaciona struktura, kao produkt postupka organizovanja, posmatra prvenstveno kao forma koja obezbeđuje implementaciju strateških planova (Popovic, 2012).

$\mathrm{U}$ tom smislu, uloga marketing menadžmenta treba da bude derivat ciljnog, strateškog i taktičkog kompleksa upravljanja organizacionim rizicima. S druge strane, realnost najvećeg broja turističkih organizacija pokazuje da organizacione strukture obično nadživljavaju planske parametre zbog kojih su izgrađene i da postaju (svesno ili spontano) autonomni entiteti upravljačkog sistema. To znači da u stvarnosti postoji vrlo jak povratni uticaj strukture na planiranje i kontrolu. Zbog toga je kompletan upravljački proces realnije shvatiti kao kontinuirani ciklus, nego kao niz faza.

$\mathrm{Na}$ profil konkretne turističke organizacije kroz koncepciju marketing menadžmenta utiče niz faktora koji dovode do organizacionih rizika. Savremeno okruženje i promene koje se u njemu dešavaju nameću menadžerskim strukturama da procesu upravljanja organizacionim rizicima prilaze koristeći i neke nove ili adaptirane pristupe. U prvom redu, pomenuti koncept može sve manje da se posmatra kao jedna od funkcija $u$ preduzeću. On jednostavno mora da postane način razmišljanja kompletne menadžerske strukture, a to mora da se odrazi i na turističku organizaciju.

Marketing menadžment kroz proces upravljanja organizacionim rizicima mora da bude vodeća poslovna filozofija, a to podrazumeva da bude totalna i integralna. Jedna od ključnih pretpostavki za ovo jeste adekvatna organizaciona menadžerska struktura. Nekome se može učiniti da je ovo koncepcija marketing menadžment "diktature", ali "diktator" je tržište, odnosno sve sofisticiraniji i zahtevniji turista. Jedini odgovor na "diktaturu" jeste totalna marketing menadžment orijentacija, kao jedini izlaz u razvoju zdravstvenog turizma u Republici Srbiji.

Već su razmatrani važniji aspekti relevantnih trendova razvoja zdravstvenog turizma $u$ Republici Srbiji u savremenom okruženju, kao i mogućnosti turističkih organizacija da im se prilogode na odgovarajući način. Jedan od najvažnijih trendova upravljanja organizacionim rizicima kroz marketing menadžment jeste fokusiranje na zahtevne turiste, odnosno stavljanje istog u centar ispitivanja. Osposobljavanje organizacije kroz marketing menadžment koncepciju za fokusiranje na zahtevne turiste, znači, u prvom redu, izgradnju adekvatne strukturne koordinacije i prateće informacione podrške. Ovaj proces zahteva da turistička organizacija prođe kroz četiri faze:

- podeljene koordinacije,

- serijske koordinacije,

- dogovorne koordinacije i

- integralne koordinacije (Gulati \& Oldruyd, 2005).

Raspoloživa informaciona tehnologija daje bazne pretpostavke za implementaciju fokusiranog pristupa zahtevnim turistima. Međutim, da bi se došlo do integralne koordinacije, potrebno je na adekvatan način razviti organizacionu strukturu marketing menadžmenta i turističke organizacije u celini. To zahteva postupnost, odnosno etapnu izgradnju koordinacionog sistema, kao veoma važnog za efikasno funkcionisanje.

Važna determinanta organizacione strukture kroz ulogu marketing menadžmenta, bazirana je na raspoloživosti kadrovskih resursa. Organizacija može da bude dobro koncipirana i adekvatna. Međutim, bitno je ko će popuniti radna mesta predviđena samim organizacionim rešenjem. Profil osoblja koje treba da bude angažovano zavisi od podfunkcije, koje traže prvenstveno kreativce, analitičare i disciplinovane izvršioce.

Nedostatak odgovarajućeg profila osoblja reflektuje se na krajnji ishod, tako da marketnig menadžment mora da bude prilagođen pomenutoj vrsti organizacionog rizika, a naprednije strukture treba programirati u situacijama kad su turističkim organizacijama na raspolaganju svi potrebni kadrovski resursi.

Relacione komponente marketing menadžmenta, odnosno zahtev da turisti budu u fokusu mikrosistema, sve više uslovljavaju da se operativno, čak i taktičko odlučivanje, na neki način demokratizuje. Brza i adekvatna reakcija preduzeća na individualne zahteve turista, traži autorizaciju odluka, koje imaju značajnu troškovnu težinu i kao takvateži njihovom smanjenju, što se odražava na organizacionu strukturu. 


\subsection{Komercijalni rizici}

Posmatrajući, kroz koncepciju marketing menadžmenta, neophodne aktivnosti koje doprinose razvoju zdravstvenog turizma u Republici Srbiji, pored organizacionih, neophodno je spomenuti i komercijalne rizike, koji se odnose na sam proizvod, njegovo organizovanje, diferencijaciju, inovaciju i ostalo.

Upravljanje ili kontrolisanje komercijalnih rizika posmatra se kroz proizvodni model organizovanja, što podrazumeva uvođenje marketing menadžera, kvalitetnog proizvoda u zdravstveno-turističku ponudu za svaku inovaciju (Popovic, 2012).

Čitav proizvodni model organizovanja, baziran je na koordinativnoj ulozi marketing menadžera koji uglavnom nema linijski, odnosno naredbovani autoritet prema funkcionalistima-specijalistima, tako da funkcioniše sistemom eksternog pregovaranja sa turbulentnim okruženjem. Po Kotleru, neki od tipičnih zadataka marketing menadžera mogu biti sledeći (Kotler \& Keller, 2006, p. 699):

- razvoj dugoročne i konkurentske strategije za proizvod,

- priprema godišnjeg marketing menadžment plana,

- rad sa oglasnim i promotivnim agencijama na razvoju poruke i programa,

- povećanje podrške proizvodu kod prodajnog osoblja i posrednika,

- prikupljanje kontinuiranih informacija o uspehu proizvoda, stavovima kupaca i posrednika, i novim problemima i mogućnostima,

- iniciranje poboljšanja proizvoda da bi se izašlo u susret promenjenim tržišnim potrebama.

Model koji je koncipiran na ulozi marketing menadžera treba da reši pitanje specijalističke zatvorenosti i da objedini sve funkcionalne resurse, $\mathrm{s}$ obzirom da je zdravstveni turizam specifična kategorija, sa zadatkom da smanji rizike u samom proizvodnom modelu. $U$ konkretnim slučajevima, uspeh ovog koncepta zavisi, od pregovaračkih i ubeđivačkih sposobnosti marketing menadžera, odnosno njegovog ličnog profesionalnog autoriteta.

$\mathrm{Da}$ bi se koliko-toliko prevazišao problem nedostatka linijskog autoriteta, unapređenje zdravstveno-turističkog proizvodnog modela moguće je kroz uvođenje proizvodnih timova ili timova za brend. Zajedničko za ova unapređenja je to što marketing menadžer više nije usamljen kao koordinator, nego prelazi na timski rad.

Unapređenje zdravstveno-turističkog proizvodnog modela može doprineti svrsishodnosti i otklanjanju slabosti, koje rezultujuiraju iz koordinacionog, a ne linijskog pristupa obavljanju aktivnosti. To se naročito odnosi na horizontalni proizvodni tim koji okuplja veći broj potrebnih specijalista. U meri u kojoj ovakve strukture mogu da se stabilizuju na duži rok, kompletan model biće uspešniji (Popovic, 2012).

Upravljanje komercijalnim rizicima kroz koncepciju marketing menadžmenta, posmatrano u celini, može dati dobre rezultate $u$ kratkom i srednjem roku, pošto je dosta tvrdo orijentisan na performansu proizvoda (marke) po kriterijumu tržišnog učešća, dok dugi rok predviđanja donosi opasnost zbog generičkih potreba, gde se gubi kontrola nad komercijalnim rizicima.

\section{ZAKLJUČAK}

Zdravstveni turizam predstavlja značajnu kategoriju u turizmu Srbije, najviše zbog kvaliteta i velikog broja izvora lekovitih voda različitih terapeutskih svojstava. Ono što se očekuje od srpskog zdravstvenog turizma jeste povećanje konkurentnosti, povećanje deviznog priliva, povećanje turističkog prometa, rast zaposlenosti, sve to u cilju transformacije Srbije u konkurentnu turističku destinaciju.

Kako bi se privukla međunarodna tražnja za zdravstveno-turističkim proizvodom Srbije, potrebno je najpre tržišno pozicionirati današnji proizvod. To je moguće jedino kroz uspostavljanje marketing menadžment koncepcije, koja će ogranizacione i komercijalne rizike držati pod kontrolom, adekvatnim zalaganjem kroz definisanje jasnih razvojnih ciljeva, koraka realizacije i efikasnog međunarodnog koordinisanja svih učesnika u procesu.

Međutim, skenirano sadašnje stanje kroz asortiman usluga u zdravstvenoj turističkoj ponudi; malu zainteresovanost privrednih i drugih subjekata iz drugih delatnosti da putem zdravstveno-turističkog proizvoda plasiraju sopstvene potrebe; relativnu neorganizovanost $\mathrm{i}$ nepovezanost nosilaca poslovne politike onih 
privrednih subjekata koji se direktno uključuju u pružanje usluga turistima; često prisustvo netržišnog ponašanja, nizak kvalitet zdravstvenoturističkog proizvoda koji izaziva negativne posledice i na ostale instrumente poslovne i turističke politike i objektivno otežava stvaranje njihove optimalne kombinacije i sl.; marketing menadžmentu omogućava prerastanje okvira klasičnih organizacionih struktura i usmerenje ka kompleksnijem načinu mišljenja, otvarajući horizonte na kojima konzervativno vođenje turističkih organizacija ne vidi svoje šanse.

Nema razvoja i progresa zdravstvenog turizma u Republici Srbiji bez definisane marketing menadžment koncepcije, kao prioriteta opšteg značaja za razvoj turizma. Marketing menadžment može biti efikasan samo ako je deo celokupnog sistema baziran na načinu razmišljanja $i$ ponašanjaturista. Politika i politički faktori manipulativnog karaktera ne smeju ostati faktori koji utiču na razvoj zdravstvenog turizma, kao i nerazvijena i nekvalitetna turistička infrastuktura i oskudna znanja iz oblasti marketing menadžmenta. Ulogu države treba usmeriti na povezivanje postojećih projekata, promocije i zakonodavstva, a lokalna partnerstva privatnog i javnog sektora usmeriti na klastere, sa zajedničkim ciljem promovisanja zdravstvenog turizma.
Marketing menadžment treba da je imperativ sadašnjeg vremena, s obzirom da je jedna od njegovih uloga u razvoju zdravstvenog turizma bazirana na kontrolisanju neizbežnih rizika. Jedino kroz marketing menadžment koncepciju rizik je moguće prihvatiti kao realnost, jer se zasniva na načelima upravljanja i poznavanju organizacione i komercijalne strukture.

Upravljanje organizacionim i komercijalnim rizicima kroz koncept marketing menadžmenta doprinosi održivom uspehu zdravstvenog turizma, što podrazumeva poslovni uspeh u kontinuitetu, održivi razvoj, socijalnu odgovornost i poslovnu etiku. Analiza predočenog stanja ukazuje da Republika Srbija ima vrlo dobre preduslove koji trenutno nisu u dovoljnoj meri iskorišteni, niti promovisani za razvoj profitabilnih zdravstvenoturističkih aktivnosti. Prirodni resursi (termalne i lekovite vode, blizina reka i jezera), bogato istorijsko, kulturno i industrijsko nasleđe, povoljan geografski položaj (naročito u pogledu korištenja saobraćajne infrastrukture), tradicionalna gostoljubivost ljudi, postojeće turističke agencije, postojeća turistička infrastruktura, multietnički karakter Srbije i multikulturne tradicije, kao i rastuća svest glavnih aktera, predstavljaju koristi koje razvoj zdravstvenog turističkog sektora donosi ukupnoj privredi.

\section{CITIRANI RADOVI}

Bass, B. (1983). Organizational Decision Making, Richard D.Irwin, Inc, Homewood, Illinois, p.13

Cavlek, N., Bartoluci, M.,Prebezac, D., \& Kesar, O. (2011).Turizam, Školska knjiga, Zagreb, p. 355-359.

Cerovic, S. (2002). Strategijski menadžment turističke privrede Srbije, Želnid press, Beograd

Cerovic, S. (2003). Menadžment u turizmu, Čigoja, Novi Sad

Gulati, R., \& Oldruyd, J.B. (2005). The Quest for Customer Focus, Harvard Business Riview,Hornung, K., Reichmann T., Diederichs, M. (1999). „Riskomanagement,“ Controling, No. 7, p. 317-325.

Jovcic, D. (2008). Stanje i perspective razvoja banjskog turizma u Srbji, Glasnik srpskog geografskog društva - sveska LXXXVIII, br. 4, Srpsko geografsko društvo, Beograd, p. 3-18

Kotler, P., \& Keller, K.L. (2006). op.cit., p. 699

Krasojevic, D. (2010). Strategic Management and Marketing in cultural Tourism of Serbia, Singidunum revija Vol. 8/No., 1 UDK: 005.21:338.48-6:7/8(497.11); 338.487:659.1(497.11), Beograd, p. 297

Kunst, I. \& Tomljenovic, K. (2011). The role of halt tourism in strengthening rural ereas competitiveness in Croatia, The Institute for tourism, Zagreb

Lazovic, M. (2011). Strategija razvoja zdravstvenog, wellness i spa ruzima Srbije-šanse i izazovi, Institut za rehabilitaciju, Beograd

Pearce, J. A., \& Robinson, R. B. (1988). Strategic Management, third ed., Irwin Home World, Illinois, p. 307 
Popovic, J. (2012).Marketinski pristup razvoju zdravstvenog turizma u Republici Srbiji, Doktorska disertacija, Univerzitet sv. Kliment Ohridski, Bitola, Fakultet za turizam i ugostiteljstvo - Ohrid, Makedonija

Popovic, J., Novovic, M., i Mihajlovic, B. (2013). Strategic Development and Promotion Guidelines of Health and Ecotourism in Serbia, Employment, education and entrepreneurship, The second International Conferernce, ISBN 978-86-6069-091-5, Beograd

Rikalovic, G. (1999). Natural Resources Economics, Đorđe Natošević, Inđija

Sekulovic, N. (2009). Kvalitet usluga i satisfakcija potrošača u turizmu, Magistarska teza, Univerzitet Singidunum, Departman poslediplomskih studija, Beograd

Zupanovic, I. (2011). Strateški menadžment turističke destinacije, Fakultet za menadžment Herceg Novi, Kotor

Datum prve prijave:

Datum prijema korigovanog rada:

Datum prihvatanja članka:
31.01.2014.

20.03.2014

14.05.2014.

\section{Kako citirati ovaj rad?}

Style - APA Sixth Edition

Popović, J., Radić, V., \& Stanković, R. (2014, 07 15). Upravljanje organizaciono komercijalnim rizicima u zdravstvenom turizmu Srbije kroz marketing menadžment koncept. (Z. Čekerevac, Ed.) FBIM Transactions, 2(2), 271-278. doi:10.12709/fbim.02.02.02.27

Style - Chicago Fifteenth Edition:

Popović, Jovanka, Vlado Radić, and Rade Stanković. 2014. "Upravljanje organizaciono komercijalnim rizicima u zdravstvenom turizmu Srbije kroz marketing menadžment koncept." Edited by Zoran Čekerevac. FBIM Transactions (MESTE) 2 (2): 271-278. doi:10.12709/fbim.02.02.02.27.

Style - GOST Name Sort:

Popović Jovanka, Radić Vlado and Stanković Rade Upravljanje organizaciono komercijalnim rizicima u zdravstvenom turizmu Srbije kroz marketing menadžment koncept [Journal] // FBIM Transactions / ed. Čekerevac Zoran. - Beograd : MESTE, 07 15, 2014. - 2 : Vol. 2. - pp. 271-278.

Style - Harvard Anglia:

Popović, J., Radić, V. \& Stanković, R., 2014. Upravljanje organizaciono komercijalnim rizicima u zdravstvenom turizmu Srbije kroz marketing menadžment koncept. FBIM Transactions, 15 07, 2(2), pp. 271-278.

Style - ISO 690 Numerical Reference:

Upravljanje organizaciono komercijalnim rizicima u zdravstvenom turizmu Srbije kroz marketing menadžment koncept. Popović, Jovanka, Radić, Vlado and Stanković, Rade. [ed.] Zoran Čekerevac. 2, Beograd : MESTE, 07 15, 2014, FBIM Transactions, Vol. 2, pp. 271-278. 